\title{
Durability of Road and Bridge Concrete and Spray-Coating Waterproof Material
}

\author{
Wei Liang
}

Fujian Chuanzheng Communications College, Fuzhou 350007, China

Corresponding Author Email: 2006016@fjcpc.edu.cn

https://doi.org/10.18280/rcma.310406

Received: 8 April 2021

Accepted: 26 June 2021

\section{Keywords: \\ road and bridge, concrete, waterproof material, durability}

\begin{abstract}
Different from traditional waterproof methods for road and bridge concrete, the spraycoating waterproof material can effectively prevent rainwater and other corrosive liquids from entering the concrete structure, and it has a few functional advantages such as anticarbonization, resistance to sulfate attack, and high elongation. Existing studies have discussed the impact of the microstructure of waterproof material on the structure of waterproof coating, the optimization of the mix ratios of waterproof material, and the influencing factors of the waterproof performance of waterproof material, etc., however, few researches have concerned about the mechanical properties of concrete after coated with the spray-coating waterproof material. Therefore, to fill in this research gap, this paper researched the durability of road and bridge concrete and the spray-coating waterproof material. At first, it analyzed the bridge deck water pressure and the internal force of the drain pipe structure under multiple drainage methods, and calculated the water pressure at the gutter inlet, the stress, and the permeability coefficient of the waterproof coating. Then, this paper elaborated on the experimental methods for measuring the durability of the road and bridge before and after coated with the spraycoating waterproof material, and introduced the methods for testing the waterproof material and the concrete. At last, this paper gave the corresponding experimental results, the analysis, and the conclusion.
\end{abstract}

\section{INTRODUCTION}

As an important part of roads and bridges, the drainage and waterproof design directly affects their normal operation, safety, and reliability [1-11]. Existing methods for improving the waterproof performance of road and bridge concrete include optimizing the mix ratios, adding mineral admixtures, and incorporating high-performance additives, etc. [12-17]. Different from above methods, the spray-coating waterproof material can effectively prevent rainwater and other corrosive liquids from entering the concrete structure, and it has a few functional advantages such as anti-carbonization, resistance to sulfate attack, and high elongation [18-21]. Such spray-coating waterproof material used for roads and bridges needs to have good alkali resistance, UV degradation resistance, cohesiveness, and wear resistance [22, 23], therefore, the research on its durability is of certain practical value.

According to the actual measurement data of concrete box girder bridge of the Shanghai-Hangzhou Expressway widening and reconstruction project, Liu et al. [24] adopted indoor tests, on-site temperature monitoring, and finite element method to study the performance of the waterproof bonding layer between the concrete bridge deck and the asphalt mixture pavement. Oh et al. [25] proposed a method for evaluating the opening resistance of joints and cracks, the method can be used for the optimization and selection of railway bridge deck waterproof materials; then they used the finite element method to analyze the typical bridge deck loading situations for assessing the joint opening range and the structure of high-speed double-track railway bridges. Mazzotta et al. [26] developed a green waterproof membrane for protecting concrete bridge decks; the membrane is composed of a recycled rubber blanket sandwiched between two layers of SBS-modified asphalt, the rubber blanket is composed of high-density elastic pads, and the elastic pads are made of rubber granules from recycled scrap tires. Kaba et al. [27] designed and fabricated a new-type high-permeability agent for the waterproofing, repairing, and reinforcement of aged concrete bridge decks; and experimental results proved that the proposed high-permeability agent can be used not only for waterproofing, but also for repair and reinforcement projects. Guo and Zeng [28] conducted pull-out tests and shear tests on epoxy resin waterproof bonding material which is widely used in bridge deck paving, and they researched the quality control under the influence of multiple factors such as pull-out rate, roughness, thickness, temperature, and humidity. To improve the design level of bridge decks, Zhang et al. [29] discussed the compatibility of epoxy asphalt concrete and the cast asphalt concrete, and used orthogonal test to study the influence of anti-corrosion layer, temperature, spraying amount and other factors on the adhesion performance of adhesive to the steel plates.

Many basic issues in the spray-coating waterproof material for roads and bridges are still unresolved, such as the influence of the microstructure of the waterproof material on the structure of the waterproof coatings, the optimization of the mix ratios of waterproof material, and the influencing factors of the waterproof performance of the waterproof material, 
besides, few researches have concerned about the mechanical properties of concrete after coated with the spray-coating waterproof material. Therefore, this paper aims to study the durability of road and bridge concrete and the spray-coating waterproof material, the main content of this paper has the following aspects: (1) Analyze the bridge deck water pressure and the internal force of drain pipe structure under multiple drainage methods, and calculate the water pressure at the gutter inlet, the stress, and the permeability coefficient of the waterproof coating; (2) Elaborate on the experimental methods for measuring the durability of the roads and bridges before and after coated with the spray-coating waterproof material, and introduce the methods for testing the waterproof material and the concrete; (3) Give the corresponding experimental results, result analysis, and research conclusion.

\section{SIMULATION OF ROAD AND BRIDGE DRAINAGE BEFORE AND AFTER COATED WITH THE SPRAY- COATING WATERPROOF MATERIAL}

The proposed material is mainly used for preventing rainwater from leaking into the bridge deck, or rainwater and snow-water from entering the bridge body and bridge girder through drain pipes and causing damages to the bridge. Table 1 shows the physical and mechanical parameters of different parts of the bridge.

Table 1. Physical and mechanical parameters of different parts of bridge

\begin{tabular}{cccccc}
\hline Material & Concrete bridge body & Grouting circle & Waterproof layer & Gutter inlet & Drain pipe \\
\hline Dry density & 1800 & 2500 & 2600 & 2600 & 2600 \\
Elastic modulus & 1.6 & 2.1 & 35 & 40 & 40 \\
Poisson's ratio & 0.5 & 0.4 & 0.3 & 0.3 & 0.3 \\
Internal friction angle & 25 & 35 & - & - & - \\
Cohesive force & 0.12 & 0.15 & - & - & - \\
Porosity & 0.23 & 0.16 & 0.77 & 0.95 & 0.12 \\
Permeability coefficient & $1.00 \times 10^{-4}$ & $1.00 \times 10^{-5}$ & $1.02 \times 10^{-2}$ & $4.75 \times 10^{-2}$ & $2.00 \times 10^{-10}$ \\
\hline
\end{tabular}

The spray-coating waterproof material has a certain impact on the drainage design and drainage performance of roads and bridges, therefore, based on the theory of fluid-solid coupling, this paper used two-dimensional numerical calculation to analyze the bridge deck water pressure and internal force of drain pipe structure under multiple drainage methods (such as overpass drainage, ordinary road drainage, and underpass drainage) after the bridge deck had been coated with the spraycoating waterproof material; the paper also compared the bridge deck water pressure of ordinary bridge drainage structure under multiple working conditions before and after the bridge deck had been coated with the spray-coating waterproof material.

When the road slope is relatively large, the road-surface rainwater flows down the slope at a large speed, it rushes through the gutter inlet, the amount of rainwater collected by the gutter is very small, and a lot of water will accumulate in the low-lying areas of the bridge. For this overpass drainage problem, at first, the gutter inlet water pressure and stress that meet solution accuracy were calculated:

Assuming: $v_{i, j}$ represents the flow speed of rainwater, $v_{e}$ represents the intensity of rainwater, $\xi$ represents the volume change of per unit volume rainwater at the gutter outlet, then there is:

$$
-v_{i, j}+v_{e}=\frac{\partial \xi}{\partial h}
$$

Assuming: $E$ represents the Biot modulus, $C O$ represents the pressure at the gutter inlet, $\beta$ represents the Biot coefficient, $\sigma$ represents the volumetric strain of bridge concrete, $B H$ represents the saturation, and $P O$ represents the drainage rate, then, there is:

$$
\frac{1}{E} \frac{\partial C O}{\partial h}+\frac{B H}{P O} \frac{\partial}{\partial h}=\frac{1}{B H} \frac{\partial \xi}{\partial h}-\beta \frac{\partial \sigma}{\partial h}
$$

Assuming: the concrete is homogeneous and isotropic, the concrete density and rainwater density are constants, $l$ represents the rainwater runoff coefficient, $\gamma_{r}$ represents the density of the rainwater, $a_{j}(j=1,2,3)$ represents the three components of gravitational acceleration, then Formula 3 gives the motion equation that describes the motion of the rainwater:

$$
v_{i}=-l\left(C O-\gamma_{r} a_{r} c_{r}\right)
$$

The change in the volumetric strain of the bridge concrete will cause changes to the pressure at the gutter inlet. Conversely, the change in the pressure at the gutter inlet will cause changes to the volumetric strain of the bridge concrete. Assuming: $\Delta \varepsilon_{i j}$ represents the stress increment, $G F_{i j}$ represents the given function, $\Delta \sigma_{i j}$ represents the total strain increment, then Formula 4 gives the incremental form of the constitutive equation of the gutter inlet medium:

$$
\Delta \varepsilon_{i j}+\beta \Delta C O \psi_{i j}=G F_{i j}\left(\varepsilon_{i j}, \Delta \sigma_{i j}\right)
$$

The relationship between the volumetric strain rate of the bridge concrete and the gradient of rainwater flow speed is:

$$
\sigma=\frac{1}{2}\left(v_{i, j}+v_{j, i}\right)
$$

This paper divided the boundary conditions in the calculation of overpass drainage method mentioned above into four types: 1) the water pressure of gutter inlet is given; 2) the component of the rainwater flow speed in a certain direction is specified; 3) the permeable boundary of bridge deck; 4) the impermeable boundary of bridge deck. Assuming: $v_{m}$ represents the component of rainwater flow speed in the normal direction outside the permeable boundary, $\tau$ represents the permeability coefficient, $C O_{B}$ represents the gutter inlet water pressure at the boundary, $C O_{S O}$ represents the gutter inlet water pressure at the seepage outlet, then Formula 6 gives 
the form of the permeable boundary:

$$
v_{m}=\tau\left(C O_{B}-C O_{S O}\right)
$$

Since the test section of the spray-coating waterproof material experiment was located at a low-lying bridge deck section in the road and bridge project, so its water pressure was even higher when the accumulated rainwater was relatively deep, this paper constructed a two-dimensional model to simulate the gutter inlet.

In engineering practice, the length and slope of the gutter inlet were consistent with the constructed numerical model. Based on the principle of equal flow, the equivalent values of the gutter inlet width and the permeability coefficient in the numerical model were determined. Assuming: $f_{1}$ represents the actual flow at the gutter inlet, $\tau_{1}$ represents the permeability coefficient, $S_{1}$ represents the area of the gutter inlet, $H Y_{1}$ represents the hydraulic gradient, $R$ represents the diameter of the gutter inlet, $K$ represents the longitudinal distance between two gutter inlets, then there is:

$$
f=\tau \cdot H Y \cdot S
$$

Assuming: in the numerical model of the gutter inlet, the flow is also $f, \tau_{2}$ represents the permeability coefficient, $S_{2}$ represents the area of the gutter inlet, $\mathrm{HY}_{2}$ represents the hydraulic gradient, $r$ represents the diameter of the gutter inlet, since the flow in engineering practice and the flow in the model are equal, both are $f$, so there is:

$$
\tau_{1} H Y_{1} S_{1}=\tau_{2} H Y_{2} S_{2}=f
$$

Since the length of the gutter inlet in engineering practice is the same with the size of gutter inlet model, and their hydraulic gradient values are the same as well, then there is:

$$
H Y_{1}=H Y_{2}
$$

Therefore, there is:

$$
\tau_{1} S_{1}=\tau_{2} S_{2}
$$

Formula 11 gives the calculation formula of the permeability coefficient of the constructed numerical model of gutter inlet:

$$
\tau_{2}=\frac{\tau_{1} \pi R^{2}}{4 K r}
$$

There are many types of laying waterproof materials and directly-spraying waterproof materials that can be used in the construction of roads and bridges, but among the various waterproof materials, waterproof coating is the most widely used material in road and bridge waterproofing projects due to its merits of indeterminate shape, convenient construction, and good overall performance. As the Chinese government is encouraging the policy of building "new infrastructure" and the construction projects of roads and bridges are developing vigorously, the amount of usage of waterproof coatings is increasing over the years.

However, due to the lag of relevant standards, the traditional road and bridge projects have to take the standards of building waterproof coatings as references, in fact, there's a big difference between the two values in terms environmental and mechanical properties. The biggest difference between the waterproofing layer of roads and bridges and the physical waterproofing of underground engineering structures lies in that the load acting on the waterproof coating film, that is, the waterproofing layer of roads and bridges needs to exert the waterproof function under the conditions that the external strain force and shear force would change continuously when vehicles pass by, especially at bends and in low-lying places, the force borne is even greater. Assuming: $l_{0}$ and $t_{0}$ represent the permeability coefficient and thickness of the waterproof material; $r_{H}, m, k, k_{H}$ respectively represent the drain pipe diameter, the number of drain pipes, the lining circumference, and the spacing between horizontal drain pipes; in the fluid calculation of rainwater flowing on the curved and skewed deck of a bridge with a small slope, assuming $\tau_{3}$ and $\tau_{4}$ represent the permeability coefficient of the drain pipe and the permeability coefficient of the concrete; in the calculation of the mechanics of the bridge structure subjected to vibration load, assuming $t_{n}$ and $\tau_{m}$ represent the thickness and permeability coefficient of the concrete bridge, then, the permeability coefficient of the waterproofing layer can be calculated by Formula 12:

$$
\begin{aligned}
& l_{n}=\frac{l_{0} t_{0}+l_{3} \cdot \frac{\pi r_{H}^{2}}{4} \cdot\left(\frac{m}{k}+\frac{1}{k_{H}}\right)+l_{4} \cdot t_{n}}{l_{0} t_{0}+\frac{\pi r_{H}^{2}}{4} \cdot\left(\frac{m}{k}+\frac{1}{k_{H}}\right)+t_{n}} \\
& \approx \frac{l_{0} t_{0}+l_{3} \cdot \frac{\pi r_{H}^{2}}{4} \cdot\left(\frac{m}{k}+\frac{1}{k_{H}}\right)+l_{4} \cdot \tau_{n}}{\tau_{n}}
\end{aligned}
$$

\section{EXPERIMENT ON THE DURABILITY OF ROADS AND BRIDGES BEFORE AND AFTER USING THE SPRAY-COATING WATERPROOF MATERIAL}

Common waterproof materials used for roads and bridges mainly include: polymer cement composite waterproof material, special waterproof coatings for roads and bridges, cement-based permeable crystalline waterproof coatings, waterproof roll-roofing materials, self-adhesive waterproof roll-roofing materials, paste-like waterproof materials, SBSmodified emulsified asphalt waterproof coatings, twocomponent polysulfide sealant (glue), SPUA (Spray Polyurea Elastomer), epoxy resin waterproof coatings, polyurethane waterproof coatings (multi-component), one-component green polyurethane waterproof coatings, and acrylic waterproof coatings, etc.

This study selected the polymer cement composite waterproof material for the modification experiment. The basic mix ratios were: 120 units of EVA (ethylene-vinyl acetate polymer) emulsion, 90 units of white cement, 2 units of defoaming agent, 20 units of talc powder, 2 units of coalescing agent, 20 units of light calcium carbonate powder, 3 units of leveling agent, 20 units of fly ash, 4 units of water reducer, 4 units of thickener, some water, 4 units of dispersant, 2 units of superfine $\mathrm{SiO}_{2}$. 


\subsection{Experimental methods of waterproof material}

In the experiment, $20 \mathrm{mg}$ of the prepared polymer cement composite waterproof material sample was placed in a synchronous thermal analyzer to obtain the thermogravimetric curve of the sample, then, based on the weight loss rate, the calcium hydroxide content was calculated. Assuming: $\mathrm{Ca}(\mathrm{OH})_{2}(\%)$ represents the calcium hydroxide content, $\eta_{W L}(\%)$ represents its weight loss rate during hydrolysis, $\mathrm{MO} \mathrm{Ca}(\mathrm{OH}) 2$ represents the molar mass of calcium hydroxide, $\mathrm{MO}_{\mathrm{H} 2 \mathrm{O}}$ represents the molar mass of water, then there is:

$$
\mathrm{Ca}(\mathrm{OH})_{2}(\%)=\eta_{W L}(\%) \times \frac{M \mathrm{O}_{\mathrm{Ca}(\mathrm{OH})_{2}}}{M \mathrm{O}_{\mathrm{H}_{2} \mathrm{O}}}
$$

Then a scanning electron microscope (SEM) and an X-ray spectrometer were used to observe the morphology of the cross-section of the waterproof coating and the changes in the void structure, and analyze the element composition of the sample. A surface contact angle meter was used to measure the static contact angle that characterizes the hydrophobic properties of the waterproof coating. A torque rheometer was used to analyze the rheological properties of the waterproof coating and the changes in viscosity under different fine powder particle contents. The drainage rate of the waterproof coating was measured with a stereo microscope. The waterproof material sample was also subjected to infrared analysis, and the infrared spectrogram is given in Figure 1. The peak at around $800 \mathrm{~cm}^{-1}$ is the vibration peak of the Si-O bond of the incorporated ultrafine $\mathrm{SiO}_{2}$, its purpose is to improve the breaking strength, adhesive strength, elongation at break, and ageing resistance. The peak at around $1600 \mathrm{~cm}^{-1}$ is the vibration peak of the hydrophilic group (-COOH), if there are too many hydrophilic groups, then the water absorption of the material will increase and the water resistance will decrease significantly.

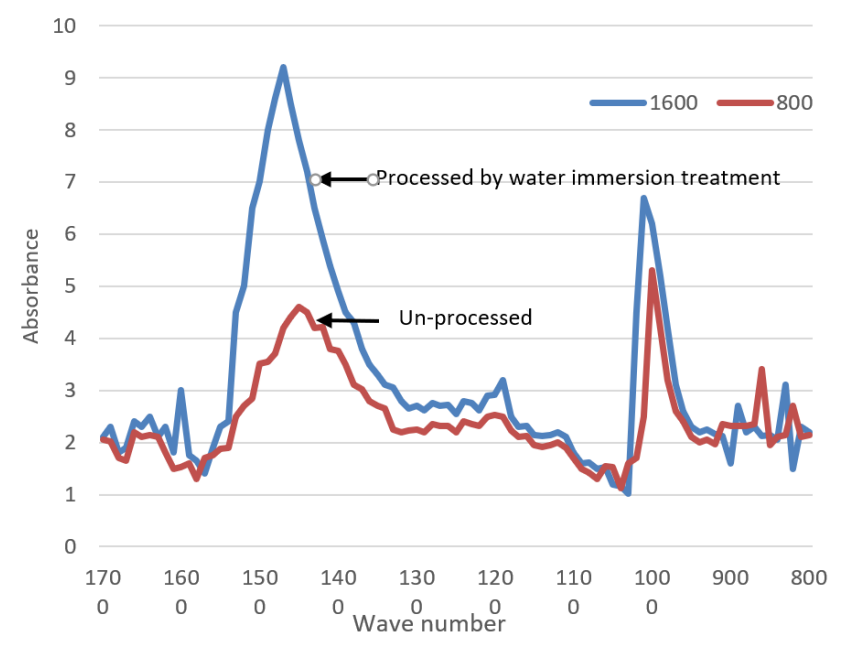

Figure 1. Infrared spectrogram of the target waterproof material

The bonding strength and tensile properties of the road and bridge concrete test pieces were measured by a universal electronic test machine. Assuming: $C S$ represents the bonding strength, $T$ represents the maximum tensile force of the test piece (unit: $N$ ), $L E$ and $W I$ represent the length and width of the bonding surface of the test piece, then Formula 14 gives the calculation formula of the bonding strength:

$$
C S=\frac{T}{L E \times W I}
$$

Assuming $S R$ represents the tensile strength, $D U$ represents the width of the middle part of the test piece, $T H$ represents the thickness of the test piece, then Formula 15 gives the calculation formula of tensile strength:

$$
S R=\frac{T}{D U \times T H}
$$

Assuming: $\eta_{E}$ represents the elongation at break, $K_{C}$ represents the distance between the marking lines when the test piece is broken, $K_{S}$ represents the initial distance between two marking lines of the test piece, then Formula 16 gives the calculation formula of the elongation at break:

$$
\eta_{E}=\left(K_{C}-K_{S}\right) / K_{S} \times 100 \%
$$

The same polymer-cement composite waterproof material was cut into test pieces of a size of $100 \mathrm{~mm} \times 3 \mathrm{~mm}$, three of them were soaked in clean water in a $2 \mathrm{~L}$ beaker, after their age was detected effectively, the surface water was wiped off to observe whether the test pieces have deterioration problems such as softening, peeling off, dissolution, or cracking, etc. Then, the three test pieces were weighed, and the water absorption rate was calculated based on the changes in mass before and after the water immersion treatment, and the changes in the mechanical properties of the waterproof coating of the test pieces were further analyzed. Assuming: $\eta_{W U}$ represents the water absorption rate of the test piece, $Q_{B}$ represents the initial mass of the test piece, $Q_{A}$ represents the mass of the test piece after water immersion treatment, then Formula 17 gives the calculation formula of water absorption rate:

$$
\eta_{W U}=\frac{Q_{A}-Q_{B}}{Q_{B}} \times 100 \%
$$

Next, the acid and alkali resistance of the polymer-cement composite waterproof material was tested. $3 \%$ supersaturated calcium hydroxide solution was prepared and taken as the alkali corrosive solution to soak the test pieces. After the age was detected effectively, the solution was removed to observe whether the test pieces have damages such as blistering, peeling off, or cracking, etc. The test on the weather resistance of the test pieces was realized by simulating cold, hot, rainy, snowy weathers and light intensity changes, then the differences in the waterproof material's weather resistance under different weather conditions were analyzed.

Experiments on the aging resistance of test pieces were divided into three types: dry and wet aging test, heat aging test, and multi-factor aging test. The experimental change factor in the dry and wet aging test was the cycle period of $12 \mathrm{~h}$ soaking in sea water solution $+12 \mathrm{~h}$ standing; the experimental change factor in the heat aging test was the cycle period of $12 \mathrm{~h} 70^{\circ} \mathrm{C}$ heat treatment $+12 \mathrm{~h}$ standard curing; and the experimental change factor in the multi-factor aging test was the cycle period of $12 \mathrm{~h} 70^{\circ} \mathrm{C}$ heat treatment $+12 \mathrm{~h}$ soaking in sea water solution $+12 \mathrm{~h}$ soaking in supersaturated calcium hydroxide solution, and the number of cycles was 30 times. After the 
cycles were over, the morphology and damage status of the test pieces were observed.

\subsection{Experimental methods of concrete}

After carbonization, the content of calcium hydroxide and calcium carbonate in the concrete of roads and bridges will change. In this study, a synchronous thermal analyzer was used to study the changes of calcium hydroxide in the concrete after sulfate attack, and an infrared spectrometer was used to study the changes of the peak of calcium carbonate in the concrete of roads and bridges after carbonization, also, an $\mathrm{x}$ ray polycrystalline diffractometer was used to analyze the changes of mineral phases of the road and bridge concrete.

In the test on the capillary suction coefficient of the concrete, the test pieces soaked in water for $1 \mathrm{~h}, 3 \mathrm{~h}, 5 \mathrm{~h}, 10 \mathrm{~h}, 15 \mathrm{~h}$ and $30 \mathrm{~h}$ were measured. Assuming $\Delta q(\varphi)$ represents the capillary water absorption of per unit area, $Q$ represents the initial mass of the test piece, $Q_{\varphi}$ represents the mass of the test piece after water immersion, $A S$ represents the water absorption area, then Formula 18 gives the calculation formula of $\Delta q(\varphi)$ :

$$
\Delta q(\varphi)=\frac{Q_{\varphi}-Q}{S}
$$

Assuming: $F C$ represents the capillary suction coefficient, $t$ represents the water absorption time, the per unit area capillary water absorption of the road and bridge concrete is positively correlated with the square root of time, namely:

$$
F C=\frac{\Delta Q(\varphi)}{\sqrt{\varphi}}
$$

In this study, the chloride ion penetration depth was adopted to evaluate the seawater erosion resistance of the test pieces made of the polymer cement composite waterproof material. In the test, the test pieces were subject to 30 cycles of test based on the dry-wet cycle method, after the cyclic corrosion was over, a press machine was used to split the test pieces along the coating surface, then $0.1 \mathrm{~mol} / \mathrm{L}$ silver nitrate solution was sprayed on the split surface once every 0.5 hours until white precipitation appeared on the split surface, the values of the chloride ion penetration depth $L p$ at $N$ different positions were recorded, Formula 20 gives the calculation formula of the average depth:

$$
L p=\frac{L p_{1}+L p_{2}+\ldots L p_{N}}{N}
$$

According to the Standard for Test Methods of Long-term Performance and Durability of Ordinary Concrete, the test pieces of road and bridge concrete were subject to carbonization test. At first, the concrete test pieces coated by the spray-coating waterproof material were placed in a carbonization test box, after the age was detected effectively, they were taken out and subjected to splitting test, then $1 \%$ phenolphthalein alcohol solution was dripped onto the split surface, and the carbonization depth was measured by a vernier caliper and recorded. Assuming: $a_{\theta}$ represents the average carbonization depth of the test piece after carbonized for $\theta$ days, $a_{i}$ represents the carbonization depth of the $i$-th measuring point on different sides, $m$ represents the total number of measuring points on the two sides, then the average carbonization depth of the test pieces could be calculated by Formula 21:

$$
a_{\zeta}=\frac{\sum_{i=1}^{m} a_{i}}{m}
$$

Also, according to the Standard for Test Methods of Longterm Performance and Durability of Ordinary Concrete, the test pieces of road and bridge concrete were subject to sulfate erosion test. At first, the concrete test pieces coated with the spray-coating waterproof material were weighed after curing, then they were put into $100 \%$ sodium sulfate solution for dry and wet cycle experiment, the cycle was: $12 \mathrm{~h}$ soaking in $100 \%$ sodium sulfate solution indoor $+10 \mathrm{~h} 70^{\circ} \mathrm{C}$ heat treatment $+2 \mathrm{~h}$ standing, a cycle was 24 hours, and the number of cycles was respectively set to 10,20 , and 30 times. Then, the concrete test pieces of each group were measured for their weight and compressive strength, and the mass loss rate and corrosion resistance coefficient of the test pieces before and after the experiment were calculated. Assuming: $\eta_{Q}$ represents the mass loss rate, when $\eta_{Q}$ is greater than 0 , the mass of the test piece increases; when $\eta_{Q}$ is less than 0 , the mass of the test piece decreases; $B Q_{o}$ represents the reference mass of the test piece before the experiment, $A Q_{i}$ represents the mass of the test piece at a certain test age, then Formula 22 gives the calculation formula of $\eta_{Q}$ :

$$
\eta_{Q}=\frac{A Q_{i}-B Q_{o}}{B Q_{o}} \times 100 \%
$$

Assuming: $C P$ represents the corrosion resistance coefficient, $K S^{\prime}$ and $K S$ represent the compressive strength of the test piece soaking in sodium sulfate solution and in curing water, then there is:

$$
C P=\frac{K S_{2}}{K S_{1}} \times 100
$$

\section{EXPERIMENTAL RESULTS AND ANALYSIS}

In this study, the evaluation index of the impermeability of the waterproof material was determined to be the water absorption rate of the concrete test piece after curing for 1 week. Table 2 shows the orthogonal test results of water absorption rate of the waterproof material. The mix ratios of defoaming agent, coalescing agent, leveling agent, and dispersant were $0.25 \%, 2.8 \%, 1.3 \%$, and $1.4 \%$ respectively. The minimum water absorption rate of the waterproof material was $7.91 \%$. At this time, the factor levels of I, II, III, and IV were respectively $\mathrm{A}, \mathrm{B}$, and $\mathrm{C}$. Then, based on intuitive analysis, the sum and range of the water absorption rate of each factor level were counted, and the result showed that, the impact degree of the content of each factor on the waterproof performance of the waterproof material from high to low is: I $>$ II $>$ III $>$ IV .

After summarizing the existing research results, this study selected the $\mathrm{pH}$, sulfate concentration, and normal contact pressure as 3 key indexes and designed a combinatorial comparison experiment based on the specific geographical 
environment and climate characteristics of the location of the studied roads and bridges to obtain the durability parameter of the spray-coating waterproof material under the operating conditions of roads and bridges.

Table 2. Orthogonal test results of water absorption rate of the waterproof material

\begin{tabular}{llllll}
\hline \multirow{2}{*}{ Test piece No. } & \multicolumn{4}{c}{ Factor level } & \multirow{2}{*}{ Water absorption rate } \\
\hline 1 & I & II & III & IV & \\
2 & A $(0.3)$ & A (1) & A $(0.5)$ & A $(0.5)$ & $9.35 \%$ \\
3 & A (0.3) & B (2) & B (1) & B (1) & $10.26 \%$ \\
4 & A (0.3) & C (3) & C (1.5) & C $(1.5)$ & $7.91 \%$ \\
5 & B (0.5) & A (1) & B (1) & C (1.5) & $10.92 \%$ \\
6 & B (0.5) & B (2) & C (1.5) & A (0.5) & $10.54 \%$ \\
7 & B (0.5) & C (3) & A (0.5) & B (1) & $8.63 \%$ \\
8 & C (0.7) & A (1) & C (1.5) & B (1) & $9.01 \%$ \\
9 & C (0.7) & B (2) & A (0.5) & C (1.5) & $10.35 \%$ \\
\hline
\end{tabular}

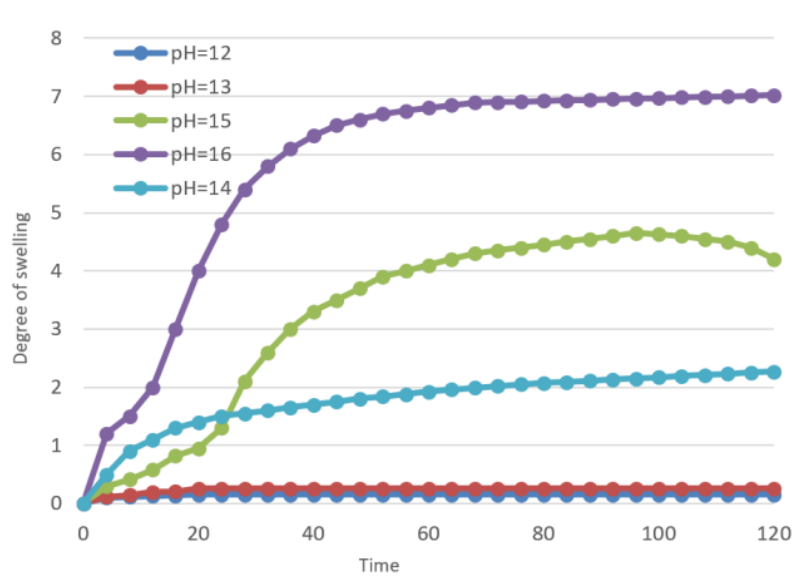

Figure 2. The change of swelling degree of the waterproof material under different $\mathrm{pH}$ values

To accelerate the test process, the immersion process of the concrete test pieces was divided into two parts: free immersion (the test pieces were directly put into the corresponding solution), and conventional immersion (the test pieces were put in a test box and then placed into the corresponding solution together). At the same time, this study introduced the variable "swelling degree", which can be equivalent to the mass change rate of the test piece before and after the immersion treatment. The swelling behavior of the spraycoating waterproof material in solutions of different $\mathrm{pH}$ values and sodium sulfate concentrations are shown in Figure 2 and Figure 3, respectively.

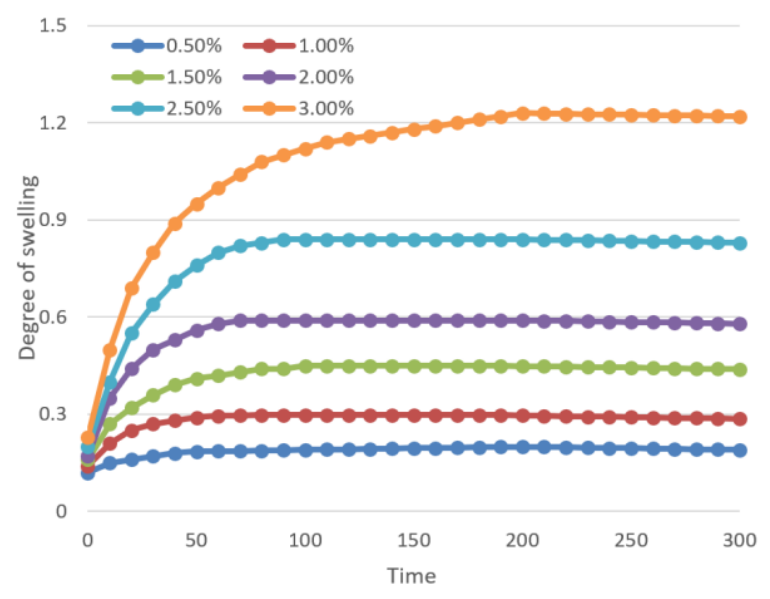

Figure 3. The change of swelling degree of the waterproof material under different sulfate concentrations
According to the results shown in the two figures, in solutions of different $\mathrm{pH}$ values and sodium sulfate concentrations, the change trends of the spray-coating waterproof material were different, but their swelling behavior basically stabilized after 3 days, thus 3-days had been set as the free immersion time of the concrete test pieces in this study.

In addition, when the $\mathrm{pH}$ value was greater than 14 , the swelling degree of the waterproof material increased to a large extent, at the same time, combining with the tests on the mechanical properties of the concrete, such as the bending strength and the compressive strength, it's indicated that the mechanical properties of the concrete test pieces had lost basically, and the waterproof coating layer had been severely destroyed. When the $\mathrm{pH}$ value was less than 13, the waterproof coating layer hadn't been destroyed temporarily, but the impact on its waterproof performance cannot be determined at the moment.

According to the results shown in Figure 3, we can know that there're certain differences in the impact of sodium sulfate concentration on the waterproof material, when the concentration of sulfate exceeded $1 \%$, the swelling degree of the waterproof coating had exceeded 0.3 , combining with the test results of the relevant mechanical properties of the concrete, the mechanical properties of the concrete test pieces had changed significantly, the waterproof performance of the coating had been weakened, which further resulted in a decrease in the relative density of the bridge concrete structure.

Table 3. Durability of the waterproof material under different compressive stress conditions

\begin{tabular}{ccccc}
\hline $\begin{array}{c}\text { Compressive } \\
\text { stress }\end{array}$ & Strain & $\begin{array}{c}\text { Time to reach } \\
\text { waterproof } \\
\text { standard }\end{array}$ & $\begin{array}{c}\text { Service } \\
\text { life }\end{array}$ & $\begin{array}{c}\text { Durability } \\
\text { retention } \\
\text { rate }\end{array}$ \\
\hline 0.5 & 0.27 & $1.12 \mathrm{~d}$ & $>1 \mathrm{y}$ & $100 \%$ \\
1.0 & 0.37 & $1.68 \mathrm{~d}$ & $>1 \mathrm{y}$ & $100 \%$ \\
1.5 & 0.43 & $2.46 \mathrm{~d}$ & $0.93 \mathrm{y}$ & $92 \%$ \\
2.0 & 0.50 & $3.54 \mathrm{~d}$ & $0.68 \mathrm{y}$ & $73 \%$ \\
2.5 & 0.52 & $4.92 \mathrm{~d}$ & $0.54 \mathrm{y}$ & $54 \%$ \\
3.0 & 0.56 & $6.35 \mathrm{~d}$ & $0.36 \mathrm{y}$ & $32 \%$ \\
3.5 & 0.62 & $>7.00 \mathrm{~d}$ & $0.25 \mathrm{y}$ & $28 \%$ \\
4.0 & 0.65 & $>7.00 \mathrm{~d}$ & $0.18 \mathrm{y}$ & $19 \%$ \\
\hline
\end{tabular}

Table 3 lists the durability of the waterproof coating under different normal contact pressures. Figure 4 shows the changes in the amount of water seepage of concrete test pieces under different compressive strain conditions. According to Table 3 and Figure 4, when the strain of the $3 \mathrm{~mm}$ waterproof coating reached 0.5 or above, the time it takes for the corresponding 
test piece to reach the waterproof standards specified in Technical Specification for Waterproofing of Construction Engineering had exceeded 3.5 days, and the amount of water seepage hadn't met the specified waterproof standards, and both the service life and the durability retention rate began to decline.

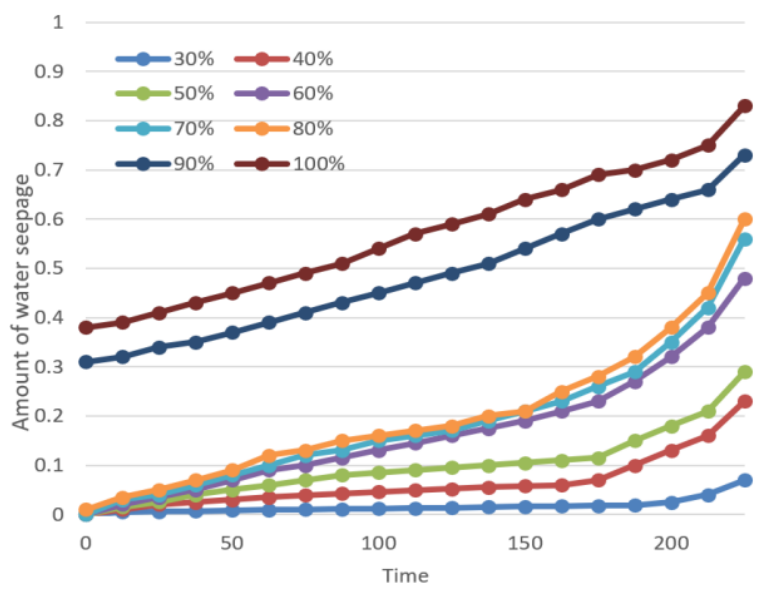

Figure 4. The change in amount of water seepage of concrete test pieces under different compressive strain conditions

Table 4. Correspondence between thickness and time

\begin{tabular}{ccc}
\hline Time & $\begin{array}{c}\text { Average thickness of } \\
\text { the test piece }\end{array}$ & $\begin{array}{c}\text { Average thickness of the } \\
\text { waterproof coating layer }\end{array}$ \\
\hline 0h & 21.6374 & 2.9575 \\
$12 \mathrm{~h}$ & 21.5427 & 2.8273 \\
$24 \mathrm{~h}$ & 21.4681 & 2.7891 \\
$36 \mathrm{~h}$ & 21.3942 & 2.6516 \\
$48 \mathrm{~h}$ & 21.3756 & 2.5568 \\
$60 \mathrm{~h}$ & 21.3148 & 2.5402 \\
$72 \mathrm{~h}$ & 21.2917 & 2.5186 \\
$84 \mathrm{~h}$ & 21.2354 & 2.5093 \\
\hline
\end{tabular}

To simulate the loss of the waterproof coating layer in common operating environment of roads and bridges, in the experiment, the $\mathrm{pH}$ value of the concrete test pieces was set to 7 , the sodium sulfate concentration was $0.2 \%$, and the normal contact pressure was $250 \mathrm{kPa}$. The data listed in Table 4 shows the changes of the thickness of the waterproof coating layer over time.

According to Table 4, the external strain and shear forces applied by vehicles driving on the roads and bridges had caused the remaining thickness of the waterproof coating layer to become thinner over time, and its waterproof performance decreased accordingly as well. Based on the data in Table 4, a scatter diagram and the corresponding fitting curve were plotted as shown in Figure 5.

According to Figure 5, with the passage of time, the decrease trend of the remaining thickness of the waterproof coating layer became gentle, and developed towards a stabilized state. If the critical strain of the waterproof coating of the concrete test pieces is 0.5 , and the critical remaining thickness of the spray-coating waterproof material is $2.6 \mathrm{~mm}$, through fitting, the predicted service life of the waterproof coating in common road and bridge environment is about 42 years.

In this study, the loss of waterproof coating layer in solutions of different $\mathrm{pH}$ values was simulated, the environment $\mathrm{pH}$ was set to different values, the sodium sulfate solution concentration was set to be a fixed value of $0.2 \%$, the normal contact pressure was also a fixed value of $250 \mathrm{kPa}$. Figure 6 shows the loss of the waterproof coating layer under different $\mathrm{pH}$ conditions.

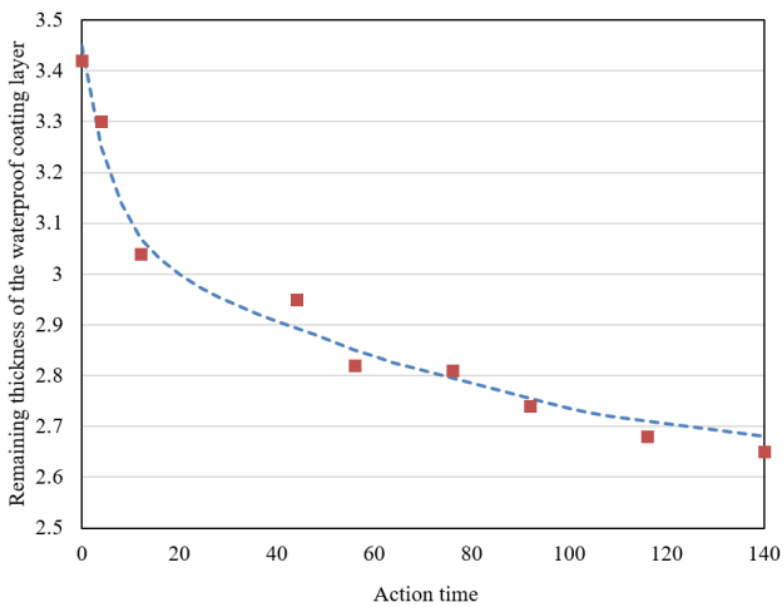

Figure 5. The change of the remaining thickness of waterproof coating layer over time

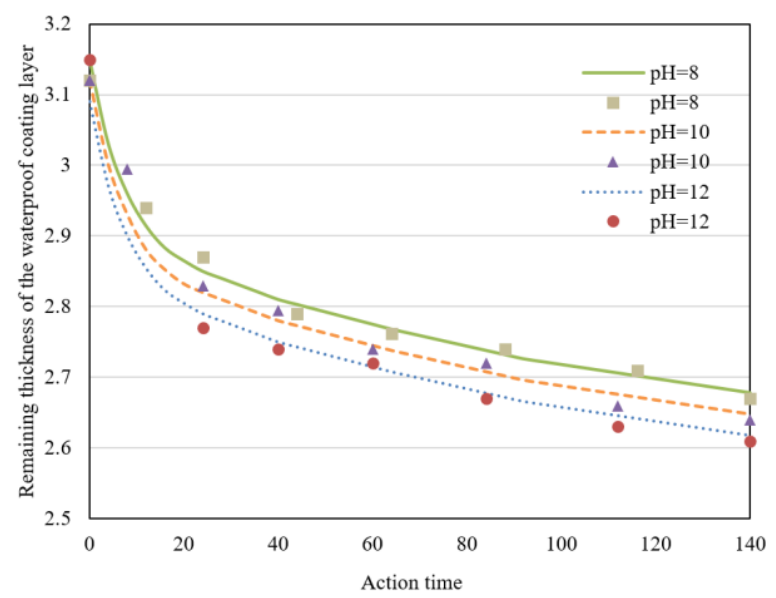

Figure 6. Loss of the waterproof coating layer under different $\mathrm{pH}$ conditions

According to Figure 6, under different $\mathrm{pH}$ values, the situation of the waterproof coating layer in the solutions was that, compared with the situation of other $\mathrm{pH}$ levels, when the $\mathrm{pH}$ was 12 , the loss thickness of the waterproof coating layer was greater, and the remaining thickness was smaller. This is because after a long-time immersion in the acidic solution, the volume of the coating layer had changed due to swelling, so the structure was more likely to be worn away. Under the longtime action of the acidic solution, the waterproof coating layer reached a thickness of $2 \mathrm{~mm}$, which is the critical remaining thickness. Then the durability fitting prediction was conducted under different $\mathrm{pH}$ conditions, and the obtained service life of the waterproof coating layer was 37.2 years, 25.0 years, 25.0 years, and 19.8 years, respectively, indicating that when the $\mathrm{pH}$ value changes in the value range of $[8,12]$, the service life of the waterproof coating layer shortens with the increase of the $\mathrm{pH}$ value. The structure of the waterproof coating became looser and more easily worn off in higher $\mathrm{pH}$ value environment, and the waterproof performance of the material had been greatly affected in later stages.

The loss of the waterproof coating layer under different sulfate concentrations was also simulated, the sodium sulfate solution was set to different concentrations, the $\mathrm{pH}$ value of 
the environment was set to be a fixed value of 7 , and the normal contact pressure was also a fixed value of $250 \mathrm{kPa}$. Figure 7 shows the loss of waterproof coating layer under different sulfate concentrations.

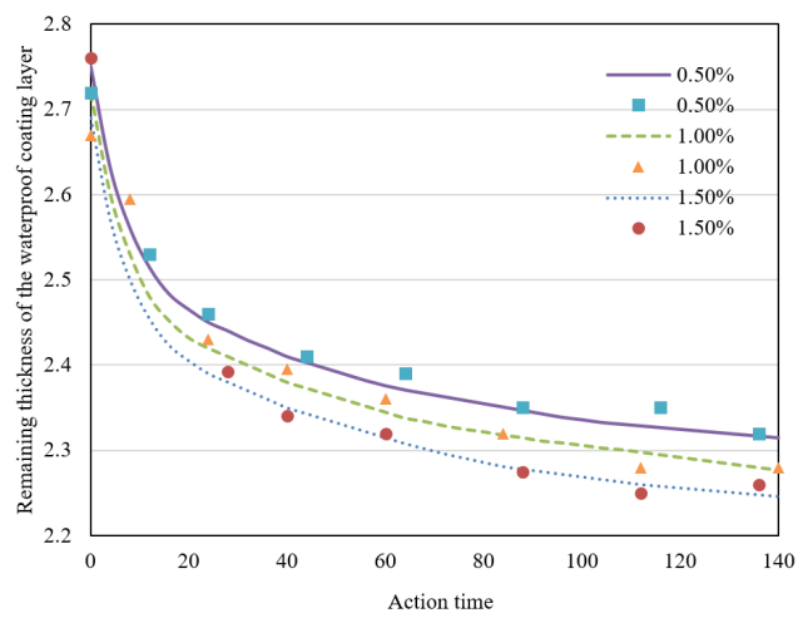

Figure 7. Loss of the waterproof coating layer under different sulfate concentrations

According to Figure 7, in environment with different sulfate concentrations, the situation of the remaining thickness of the waterproof coating layer under the action of the solution was: compared with the solution of other sulfate concentrations, when the sulfate concentration was $1.5 \%$, the loss of the thickness of the waterproof coating layer was greater, and the remaining thickness was smaller, indicating that when the sulfate concentration changes within the value range of $[0.5 \%$, $1.5 \%$ ], the waterproof coating layer swells to varying degrees, and its stiffness is greatly reduced as the swelling degree increases.

Under the long-time action of the sodium sulfate solution, the waterproof coating layer reached its critical remaining thickness of $2 \mathrm{~mm}$, then durability fitting prediction was conducted under different sulfate concentrations, and the obtained service life of the waterproof coating layer was 31.5 years, 22.4 years, and 17.4 years, respectively, indicating that under the action of high-concentration sodium sulfate solution, the stiffness decrease was more significant, the impact on waterproof performance was greater, and the material was more easily worn off by the driving vehicles.

Table 5. Calculation results of waterproof safety factor of the concrete structure

\begin{tabular}{ccc}
\hline $\begin{array}{c}\text { Position of the } \\
\text { cross-section }\end{array}$ & $\begin{array}{c}\text { Safety } \\
\text { factor }\end{array}$ & $\begin{array}{c}\text { Reference range of the } \\
\text { safety factor }\end{array}$ \\
\hline Bridge span & 10.75 & $>3.7$ \\
Bridge pier & 5.23 & $>2.5$ \\
Bridge deck & 5.46 & $>2.5$ \\
Bridge abutment & 3.52 & $>2.5$ \\
\hline
\end{tabular}

At last, this paper calculated the waterproof safety factor of the concrete structure of the studied roads and bridges, the results are given in Table 5 . The safety factor of the bridge span is the largest, the safety factor of the bridge abutment is the smallest, and the waterproof safety factor of each part of the concrete structure of the studied roads and bridges could meet the requirements of the specification, which has proved that, after the spray-coating waterproof material had been used in the studied road and bridge waterproof engineering project, the waterproof safety of the waterproof and drainage structure could reach the design requirements.

\section{CONCLUSION}

This paper studied the durability of road and bridge concrete and the spray-coating waterproof material. First, the paper analyzed the bridge deck water pressure and the internal force of the drain pipe structure under multiple drainage methods, and calculated the water pressure at the gutter inlet, the stress, and the permeability coefficient of the waterproof coating layer. Then, it elaborated on the experimental methods for measuring the durability of the road and bridge concrete before and after coated with the spray-coating waterproof material, and introduced the methods for testing the waterproof material and the concrete. After that, combining with the orthogonal test of the water absorption rate of the waterproof material, this paper gave the rank of the impact degree of the content of each factor on the waterproof performance of the waterproof material, and a variable "swelling degree" was introduced to discuss the swelling degree change and loss of the waterproof material under different sulfate concentrations and $\mathrm{pH}$ values. At last, the durability and water seepage changes of the waterproof coating under different compressive stress conditions were analyzed, and relevant diagrams were plotted to show the experimental results and analysis conclusions.

\section{REFERENCES}

[1] Li, Y.L., Tan, Y.Q. (2012). The connection properties of rubber asphalt waterproofing adhesive layer in bridge deck pavement. Applied Mechanics and Materials, 142: 169-172.

https://doi.org/10.4028/www.scientific.net/AMM.142.1 69

[2] Ai, C., Huang, H., Rahman, A., An, S. (2020). Establishment of a new approach to optimized selection of steel bridge deck waterproof bonding materials composite system. Construction and Building Materials, 264: 120269 . https://doi.org/10.1016/j.conbuildmat.2020.120269

[3] Zhang, F., Li, M., Wang, T. (2020). Performance of composite waterproof cohesive layer on cement concrete bridge. Journal of Harbin Institute of Technology, 52(3): 26-32.

[4] Ai, C., Huang, H., Rahman, A., An, S. (2020). Establishment of a new approach to optimized selection of steel bridge deck waterproof bonding materials composite system. Construction and Building Materials, 264:

120269 .

https://doi.org/10.1016/j.conbuildmat.2020.120269

[5] Crispino, M., Flintsch, G., Giustozzi, F. (2010). Lifecycle analysis of a new composite material for bridge pavement waterproofing. In 5th International Conference on Bridge Maintenance, Safety and Management, pp. 18.

[6] Xu, Q., Zhou, Q., Medina, C., Chang, G.K., Rozycki, D. K. (2009). Experimental and numerical analysis of a waterproofing adhesive layer used on concrete-bridge decks. International Journal of Adhesion and Adhesives, 29(5):

525-534. 
[7] Cao, W.D., Yao, Z.Y., Liu, S.T., Cui, X.Z. (2009). Performance of composite modified asphalt with Trinidad lake asphalt used as waterproofing material for bridge deck pavement. Journal of Testing and Evaluation, 37(5): 463-467.

[8] Guo, M., Tan, Y., Wang, L., Ye, Z., Hou, Y., Wu, J., Yang, H. (2018). Study on water permeability, shear and pull-off performance of waterproof bonding layer for highway bridge. International Journal of Pavement Research and Technology, 11(4): 396-400. https://doi.org/10.1016/j.ijprt.2017.09.013

[9] Wan, C., Shen, A., Zhao, X., Xun, C. (2017). Grey target optimization of waterproof adhesive materials for bridge deck pavement with comprehensive performance. Journal of Building Materials, 20(3): 408-412.

[10] Zhang, M., Hao, P., Men, G., Liu, N., Yuan, G. (2021). Research on the compatibility of waterproof layer materials and asphalt mixture for steel bridge deck. Construction and Building Materials, 269: 121346. https://doi.org/10.1016/j.conbuildmat.2020.121346

[11] Jin, W., Zhao, Y., Wang, W., He, F. (2021). Performance evaluation and optimization of waterproof adhesive layer for concrete bridge deck in seasonal frozen region using AHP. Advances in Materials Science and Engineering. https://doi.org/10.1155/2021/5555535

[12] Lukinsky, O.A. (2011). Hermetic sealing in bridge engineering and culvert waterproofing. Polymer Science $\begin{array}{llll}\text { Series } & \text { D, } & \text { 4(1): }\end{array}$ https://doi.org/10.1134/S1995421211010126

[13] Zhang, H., Gao, P., Zhang, Z., Pan, Y. (2020). Experimental study of the performance of a stressabsorbing waterproof layer for use in asphalt pavements on bridge decks. Construction and Building Materials, 254:

119290.

https://doi.org/10.1016/j.conbuildmat.2020.119290

[14] Liu, M., Han, S., Yang, H., Wu, X. (2020). The applicability of different waterproof adhesive interlayer for bridge deck pavement. Journal of Shenzhen University Science and Engineering [ISSN: 10002618/CN: $\quad 44-1401 / \mathrm{N}], \quad 37(1)$ : $1-110$. https://doi.org/10.3724/SP.J.1249.2020.01103

[15] Qiu, Y., An, S., Rahman, A., Ai, C. (2020). Evaluation and optimization of bridge deck waterproof bonding system using multi-objective grey target decision method. Road Materials and Pavement Design, 21(7): 1844-1858. https://doi.org/10.1080/14680629.2019.1568288

[16] Hu, H.B., Liu, G., Qian, Z.D., Liu, Y., Wu, X.Y. Experimental study of waterproof bonding layer for concrete deck of Qingshan Changjiang River highway bridge in Wuhan. Bridge Construction, 50: 57-62.

[17] Xu, Y., Lv, X., Ma, C., Liang, F., Qi, J., Chou, Z., Xu, S. (2021). Shear fatigue performance of epoxy resin waterproof adhesive layer on steel bridge deck pavement. Frontiers in Materials, 7: 469. https://doi.org/10.3389/fmats.2020.618073

[18] Al-Rashed, R., Al-Jabari, M. (2021). Concrete protection by combined hygroscopic and hydrophilic crystallization waterproofing applied to fresh concrete. Case Studies in Construction Materials, 15: e00635.

[19] Gao, J., Geng, Y., Li, S., Chen, X., Shi, D., Zhou, P. (2021). Effect of silane emulsion on waterproofing and Anti-icing performance of foamed concrete. Construction and Building Materials, 301: 124082.

[20] Oh, K.H., Kim, S.Y. (2021). Strain concentration ratio analysis of different waterproofing materials during concrete crack movement. Materials, 14(16): 4429. https://doi.org/10.3390/ma14164429

[21] Matar, P., Barhoun, J. (2020). Effects of waterproofing admixture on the compressive strength and permeability of recycled aggregate concrete. Journal of Building Engineering, 32 : 101521. https://doi.org/10.1016/j.jobe.2020.101521

[22] Al-Rashed, R., Jabari, M. (2020). Dual-crystallization waterproofing technology for topical treatment of concrete. Case Studies in Construction Materials, 13: e00408. https://doi.org/10.1016/j.cscm.2020.e00408

[23] Zhou, X.X., Yang, Z.Z., Xu, Y.J., Wang, L., Sun, H.B., Wang, Y.Z., Du, Q.Y., Yue, H.Z. (2019). A review on waterproofing agent of lightweight porous concrete. Cailiao Daobao/Materials Reports, 33(8): 2546-2551.

[24] Liu, Y., Wu, J., Chen, J. (2014). Mechanical properties of a waterproofing adhesive layer used on concrete bridges under heavy traffic and temperature loading. International Journal of Adhesion and Adhesives, 48: 102-109.

[25] Oh, K.H., Kim, S.Y., Park, Y.G. (2020). Joint-or crackopening resistance evaluation of waterproofing material and system for structural sustainability in railroad bridge deck. $\quad$ Materials, $13(19)$ : 4229. https://doi.org/10.3390/ma13194229

[26] Mazzotta, F., Lantieri, C., Vignali, V., Simone, A., Dondi, G., Sangiorgi, C. (2017). Performance evaluation of recycled rubber waterproofing bituminous membranes for concrete bridge decks and other surfaces. Construction and Building Materials, 136: 524-532. https://doi.org/10.1016/j.conbuildmat.2017.01.058

[27] Kaba, K., Nagata, Y., Hiraoka, T., Gyakushi, H., Ishigaki, T. (2016). Development of high penetration agent and its application to concrete bridge deck waterproofing, repair and reinforcement. In IABSE Congress: Challenges in Design and Construction of an Innovative and Sustainable Built Environment, Stockholm, pp. 11821189. https://doi.org/10.2749/stockholm.2016.1169

[28] Guo, L., Zeng, G. (2021). Study on mechanical properties of typical steel bridge deck pavement waterproof bonding system. In Journal of Physics: Conference $\quad$ Series, $1802(2)$ : 022018. https://doi.org/10.1088/1742-6596/1802/2/022018

[29] Zhang, M., Hao, P., Men, G., Liu, N., Yuan, G. (2021). Research on the compatibility of waterproof layer materials and asphalt mixture for steel bridge deck. Construction and Building Materials, 269: 121346. https://doi.org/10.1016/j.conbuildmat.2020.121346 